\title{
Construction of Evaluation System on Multimedia Educational Software
}

\author{
Zhiyan JIA ${ }^{\text {a1 }}$, Xie Han ${ }^{\mathrm{a} 2}$ \\ ${ }^{a}$ School of Electronics and Computer Science and Technology North University of China Taiyuan Shanxi \\ 030051, China
}

\begin{abstract}
With the popularization of multimedia technology in the application on teaching, the actual application on teaching software has become a major problem that computer-assisted instruction (CAI) in-depth developed. Constructing a scientific, objective, and fair evaluation system of multimedia teaching software has become imperative. By combining current characteristics of CAI and various evaluating indicator at home and abroad, a more reasonable evaluation system is proposed in this paper. Experimental data show that the evaluation system is feasible and effective, and has a wide range of applications.
\end{abstract}

Index Terms: Multimedia teaching software; evaluating indicator; weight

(C) 2013 Published by MECS Publisher. Selection and/or peer review under responsibility of the International Conference on E-Business System and Education Technology

\section{INTRODUCTION}

At present, the rapid development of multimedia technology and the rapid spread of information technology, multimedia technology and network technology integrate at a high degree, so that a revolutionary change have taken place in the field of education. Education has evolved from the traditional classroom of blackboard and chalk to multimedia software teaching, online teaching, distance education, and so on. As soon as possible to establish a scientific, objective and impartial evaluation system of multimedia educational software and quantify for the actual operation, have become a most urgent problem. Many companies and departments have their own evaluation criteria and requirements, but the relative and subjective are too much, so they can not meet the general evaluation. Now, the author describes and compare to a variety of domestic and international evaluation methods in order to arrive at a suitable simple evaluation index system.

\section{Evaluation method of domestic and foreign}

Four basic software evaluation methods are generally used at broad: analytical review, evaluation index system, questionnaire interview methods and teaching test method. These four methods have different

* Corresponding author:

E-mail address: ${ }^{1}$ jiazhy@ @uc.edu.cn, ${ }^{2}$ hopenxfg@nuc.edu.cn 
characteristics, so you can get different forms of content detailed in the evaluation results from different angles and dimensions of the assessment. Analytical review requests analytical staff to write the whole evaluation report according to overall impression of the software. Evaluation index system requests analytical staff to scores for the various features of the software according to a specific set of evaluation coefficients, and define the software's quality and technical level according to the score. Questionnaire interview method, also known as "observation", observes the whole process that students using the software , and records student responses, and then lets the students fill out attitude questionnaires which have been designed in advance, and conducts random interviews to obtain their attitudes and perceptions about software. Teaching test methods, also known as experimental test, requests the evaluators to design an appropriate testing program according to the teaching goals of the software and characteristics of the user, and implement the pretest, posttest learning software applications, memory retention testing, and other steps to test students how grasp the knowledge and skills of the software, and finally determines the effectiveness of teaching software.

Evaluation practice at abroad, usually integrates application of several methods to compensate for the inadequacies of each other. Domestic evaluation activity of CAI software starts more late, and gradually forms a three-tier assessment system after ten years of exploration. General process is that: first of all, a team of assessment officers checks the stability and reliability of software, and checks out unqualified software; and then subject specialists and system experts of CAI system evaluate the education system of the CAI system; finally, assessments of the experts are gathered in order to determine the software level. The Evaluation results of this evaluation model is basically relying on the experts to determine by their attitude on the software, so professional is more high, and subjective is also more high, and its final evaluation is not necessarily suitable for a wide range application of excellent software.

\section{The principles of evaluation indicator established}

For the production and application of multimedia teaching software, its ultimate goal is to complete the teaching task more efficiently, and improve teaching quality. Therefore, the principle should be evaluated both in terms of teaching and learning.

First, multimedia teaching software must enhance teaching effectiveness and improve the quality of teaching. Multimedia educational software combine the text, graphics, animation, video, audio and other media productions through the computer in order to inspire multiple senses of learners and initiate visual knowledge to learners to enhance their understanding and memory at same time they learn, thereby enhance the quality of teaching. Therefore, the producer of the software should be subject to the actual teaching needs, and can not focus too much on braveness of software, while should focus too much on the integration of scientific, educational, teaching.

Second, multimedia teaching software must enhance stimulate interest of learners and enhance their self-learning's ability. Interest is the best motivation to learn. Multimedia teaching software can integrate sound, light, and electricity to provide visual information, and overcome the traditional teaching difficulty that some abstract, conceptual direction is difficult to explain, and can greatly mobilize the interest of learners, and has a good human-computer interaction function to facilitate the review of the learner and self-learning course used at any time. Therefore, multimedia teaching should focus on in the production of technical, artistic and other issues.

\section{4. the construction of evaluation system}

\section{A. Construction Method}

Currently, the access method of evaluation indicator has generally two types: one is engaged in teaching administrative staff, software production staff, teaching staff and other experts based on personal experience, to make a number of indicators relatively close to the project, and then personnel of statistics sum them and fed back the results to the experts, so that they can further emend indicators according to self and other people's 
views. The process must repeat until no significant difference. This access method is called Delphi (Delphi) evaluation. Another method is to obtain the overall objective of teaching as the criterion, and gradually decompose until target specific sub-groups can be measured, and can obtain a detailed evaluation. This method is put forward by the American educator: Taylor (RW Tyler) and Bloom (BS B loom). In this paper, a new evaluation system is put forward to combine above two methods. The evaluation system relies on the latter approach first, and then constructs the advice of the experts.

\section{B. Construction and Evaluation of weight}

Weight is a value of software's status and role in the evaluation system. The greater weight represents its greater importance in the index system. In general, the method of determining the weights is to organize the experts to define the weight coefficients according to their own experiences, and then consolidate by the statistical evaluation personnel. To avoid making weight coefficient distribution unreasonable because of subjective attitude of the personal, each goal should be divided into important indicators and the general indicators by a group of experts. In terms of evaluating a software as excellent, good, qualified and unqualified grades, important indicators and general indicators must be given their numbers. Respectively, the average number of points must be achieved, or A, B, C, D such levels must be taken the level of each type of provision to meet an important indicator of the number of $\mathrm{A}$, less than the number of $\mathrm{D}$ and so on, that would be effective to avoid the subjective bias problem.

\section{Construction of indicator system}

These principles is lined to develop a set of quantitative evaluation system for reference:

\section{A. educational (20\%)}

Explicit purpose of teaching, appropriate target, clear theme is in line with educational policy and closely linked to syllabus $(20 \%)$;

Appropriate topics and selection, is able to highlight the characteristics of multimedia teaching and consistent with the principle of reasoning layman (40\%);

Rich and comprehensive teaching content, complete structure, difficult dispersion, operating typical ,visual image, and strong inspiration can improve learning efficiency (40\%).

\section{B. $\quad$ teaching (30\%)}

Importing stimulate interest of students in learning, and reflecting the link of old and new knowledge (10\%);

Teaching the main part to clearly solute the importance and difficulty of teaching, and ensuring students to understand and accept easily (30\%);

Teaching method can reflect the teacher-led instruction and student's learning process, pictures, audio and video are used to perform appropriate teaching content (20\%);

Design of the concise summary focuses on the vital, and can reflect the structure of this chapter and the essence of knowledge (10\%);

The design of exercises include the main points, and distinguish between the basic point, focus and difficult point $(10 \%)$;

Appropriate and the amount of information has expanded to meet the students' self study (20\%).

\section{Technique (20\%)}

Multimedia technology: images, sounds, text design is reasonable, convergence and smooth, clear screen, clever animation, vivid colors, bold text, voice standards, appropriate volume, moderate speed to keep up with the screen $(20 \%)$;

Software makes: suitable for network operation environment, remote teaching and learning can be achieved 
with good portability, scalability, sharing, system compatibility, the running reliability, fault tolerance and ease of maintenance $(30 \%)$;

Interactivity: Interactive features strong, controllable, jumping flexible navigation strategy is good, with the help function to help more will have a clear goal $(30 \%)$;

Operational use of: ease of installation is simple, reliable; simple, unified function keys (20\%).

\section{D. science (15\%)}

Correct content, logical rigor, clear level, exposition of scientific principles and reasoning is accuracy $(50 \%)$;

Accurate written, standardized terminology according with international or national industry standard (20\%);

Realistic effects of animation is able to accurately reflect the scientific principles (30\%).

\section{E. $\operatorname{art}(7 \%)$}

Sophisticated ideas, clear composition, flexible and smooth screen $(50 \%)$;

Reasonable color, rational and beautiful layout (25\%);

Appropriate voice and beautiful tone according with laws of cognition (20\%);

Streamlined text, font size, color, shape is appropriate coordination with the overall mix (5\%).

\section{F. economic practicality (8\%)}

Production of low cost, high efficiency, low maintenance costs and long life cycle (30\%);

A convenient real-time help functions and detailed instructions manual (30\%);

Modular design, easy to organize a different lesson plans based on the content of teachers $(40 \%)$.

\section{Description of evaluation application}

Evaluation system starts by the school staff of teaching and research organization, and the evaluator quantify according to the two officers indicators. Finally, related explanations are given by statistics.

The formula for the evaluation factor is : $C_{i}=\Sigma a_{j} n_{j} / 5 N$

In which, $\mathrm{C}_{\mathrm{i}}$ is evaluation coefficients, $\mathrm{a}_{\mathrm{j}}$ is score of grade, $\mathrm{n}_{\mathrm{j}}$ is the number of people for assessments of the level, and $\mathrm{N}$ is the total number of people involved in assessment. In fact, evaluation system has two step. One is to evaluate the six attributes of the courseware. Through this evaluation, you can learn more about the merit and demerit of the courseware on each feature. Second is to comprehensively evaluate the courseware, the evaluation coefficient of courseware evaluation can be gotten through evaluation indicator in terms of levels of each dimension. By further quantification, you can compare the quality of courseware. According to the different purposes of courseware evaluation, one of two evaluation methods can be selected to diagnose courseware.

\section{Reference}

[1] Fengguang XIONG, Xie HAN. Design and implementation of geological hazard forecast system based on WebGIS. 2009 International Conference on Computational Intelligence and Software Engineering, CiSE 2009, 2009 , Page(s): 4-711 - 4-715

[2] Fengguang XIONG, Xie HAN. Research and implementation of heterogeneous data integration based on XML, Proceedings of 9th International Conference on Electronic Measurement and Instruments, ICEMI 2009 , Page(s): 4-711 - 4-715

[3] Fengguang Xiong; Zhiyan Jia. Research and implementation of synchronized LXI interface. International Conference on Computer Application and System Modeling (ICCASM), 2010,10-27 - 10-30

[4] Yungwei Hao. Does multimedia help students answer test items? Computers in Human Behavior, Volume 
26, Issue 5, September 2010, Pages 1149-1157

[5] Herng-Yow Chen, Kuo-Yu Liu. Web-based synchronized multimedia lecture system design for teaching/learning Chinese as second language Original Research Article. Computers \& Education, Volume 50, Issue 3, April 2008, Pages 693-702

[6] Pei-Chen Sun, Hsing Kenny Cheng. The design of instructional multimedia in e-Learning: A Media Richness Theory-based approach Original Research Article. Computers \& Education, Volume 49, Issue 3, November 2007, Pages 662-676 